REFLECTIVE PIECE

\title{
Growing into Pedagogical Partnerships Over Time and Across Disciplines: My Experience as a Non-STEM Student Consultant in STEM Courses
}

Natasha Daviduke, Political Science graduate, Haverford College, USA

Contact: andaviduke@gmail.com

\section{INTRODUCTION}

"I don't know anything about chemistry," I thought, as I read an email informing me that my first placement as a student consultant with the Students as Learners and Teachers (SaLT) Program would be in an organic chemistry lab. I was a political science major. What could possibly qualify me to work with a STEM professor?

Following that first placement, I was partnered with an interim faculty member who was teaching an introductory statistics class for non-majors. My third and final partnership was with a physics professor who taught an entry-level course for aspiring majors and pre-med students.

In this essay, I consider my role as a student consultant across these three partnerships. Each placement challenged me to adapt to new and unfamiliar subjects, different classroom cultures, and a variety of goals and intentions for the partnership. All three partnerships proved to be valuable opportunities for personal growth and development in my practice as a consultant, and together they convinced me that my non-STEM identity was an asset to my faculty partners and our work together.

\section{ADJUSTING TO AN UNFAMILIAR LEARNING SPACE}

At the beginning of my first partnership, I struggled to adapt to the unpredictable nature of the lab. Because most of my knowledge about classroom pedagogy was limited to discussionheavy, professor-centric spaces in the social sciences, I had to identify possible points for pedagogical growth within a largely independent, project-based environment, while accounting for the entirely unfamiliar vocabulary and content of organic chemistry. I took careful, timestamped notes of my faculty partner's movements and exchanges, occasionally making observations about her questioning style or method of explanation; furthermore, I kept track of which working groups collaborated with her, in order to measure the consistency of professor interaction and attention throughout the duration of the lab. After exploring various approaches, I realized that the richest opportunity for my involvement was in observing the brief, ubiquitous teaching conversations between my partner and the students, as well as 
directly troubleshooting more macro aspects of the course with my professor, such as the involvement of teaching assistants, grading practices, and course organization. These topics led to fruitful conversations and proved to be points of interest for both me and my partner.

I was fortunate to have a skilled, ambitious, and reflective faculty partner who approached our conversations with enthusiasm; she went to great lengths to effect change in her class, which allowed me to grow in my capacity as a consultant and overcome many of my initial misgivings. My partner was deeply engaged with our work together and she fostered a strong culture of collaboration in our partnership from the outset. She carefully read through my notes and recorded her own reactions before our meetings to ensure that we had a starting point and a structure for our conversations. Our discussions ranged from the minutia of the course, to a college's role in supporting students, to the challenges of being first-year faculty, to personal stories. Through the encouragement and affirmation that we gave one another, I discovered that my perspective as a non-STEM student enhanced my observational powers, allowed me to draw suggestions from a broad array of pedagogical concepts, and enabled me to convey the viewpoint of a novice in the subject area.

The doubt I felt at the start of the semester forced me to adapt and expand what I understood to be my role in the partnership. My lack of confidence in the value of my own contributions had narrowed my perspective, limiting the scope of what I felt I could do as a consultant. With the constant support, respect, and advice of my peers in the SaLT Program, I was able to push past these doubts and trust that the partnership would evolve and lead us to meaningful insights, without me trying to steer it in the direction I believed it should go.

\section{RETHINKING THE ROLE OF STUDENT CONSULTANT}

At the start of my first partnership, I observed that my partner was an excellent professor and that her students appreciated her, but believed there was nothing of substance I could offer. Stuck in my own assumptions about the importance of content knowledge in a pedagogical partnership, I did not yet realize what I could offer from outside the discipline. My faculty partner, on the other hand, had no doubts about my value as an observer and collaborator. When asked what was most beneficial about working with me as a student consultant, she shared this insight:

Teaching a subject for the first time is very much akin to conducting an experiment: you simply have to try new things and approaches and observe what works and what doesn't. Having an extra pair of eyes in the laboratory made the observation process much easier-especially since, with many things going on in the lab, it is often difficult to make notes on how students respond to the teaching approach while at the same time answering their questions, troubleshooting their issues and making sure experiments are conducted safely. It was, therefore, a great asset to have a student partner keep notes and read them to me in the calmer environment of my office. I was surprised at how many things you noted that I simply didn't catch and how detailed your notes were. It definitely boosted my confidence as a first-time teacher of the organic chemistry laboratory and was a great source of feedback regarding what practices work with the students. When I taught the course again, I felt very confident 
about my ability to lead the class and it manifested into an extremely positive learning environment.

In the early weeks of our partnership, I worried that if I did not have substantive observations to discuss in our meetings, I had failed my faculty partner. I had a narrow idea of what was useful, and it took me time to realize that consulting did not mean I had to have "answers" or incite change. In reading her reflections on our partnership now, I have a deeper understanding of how my observations and supportive presence bolstered her self-assurance as an educator.

My first partnership was instrumental in building my self-confidence as a consultant. It was reassuring to know that what felt like superficial notes to me were valuable records to my partner. She appreciated being able look back on detailed descriptions of her teaching and reflect on what fit with her intentions for the course and what required fine-tuning. Once I accepted that consulting meant I could take on a variety of roles within a partnership-that I was not a failure if I operated differently than more seasoned consultants - I fell into a comfortable supporting role. It was rewarding to listen to my partner share her concerns about the class and the department, and to affirm her practice. She was a strong professor, meticulous in her planning and responsive in her instruction. We had wonderful conversations about teaching and learning, and we supported each other in building self-assurance. My apprehensions about working with a STEM professor dissipated as I realized that we could discuss pedagogy entirely apart from the specific content of the class, which was something I felt far more prepared to explore. It was a positive, constructive way to grow into my role as a consultant and recognize the value of my presence and perspective.

\section{COMING TO HAVE CONFIDENCE IN THE VALUE OF MY PERSPECTIVE}

My first partnership allowed me to walk into my second placement with confidence. It was a lecture-style class with time for discussion, which was both a comfortable environment for me and a context that lent itself easily to observation and adjustment. I identified strongly with the students in the class, who were predominantly humanities and social science majors taking math for distributional credit. Like them, I had sat in those same seats, wondering how basic STEM concepts were relevant to my education and goals. I knew what it felt like to simply want a required credit. I knew how frustrating it could be to make a connection to the social sciences and have it be brushed aside. Having been in these students' shoes, I had a valuable perspective that informed my feedback throughout my second partnership. With the identities of these learners in mind, my partner and I worked to build space into the course for deeper discussion, attempted to place concepts and examples into a relevant context, and strived to provide a clear structure for academic success.

My partner was new to teaching and therefore open to brainstorming and testing classroom practices. She placed a great deal of trust in my observations and ideas, which helped us to build a strong, creative partnership in which I felt able to take more initiative. While my first partnership helped me to grow into my role, my second was an exciting opportunity to develop greater depth of pedagogical knowledge, take risks, and advance my practice as an observer and collaborator. Where before I had struggled to make meaningful 
observations, I was now challenged to refine a multitude of feedback into a few digestible, salient points. My partner and I tackled a broad array of issues, making a concerted effort to incorporate new practices into the course without throwing students off track. We discussed strategies for encouraging more balanced participation, responding to difficult questions, curbing instructional tangents, creating opportunities for discussion in a large STEM course, engaging non-STEM students, making materials relevant and accessible, and setting clear objectives around course content. My partner's desire to grow as an educator created space for me to critically observe her class, voice ideas, and bring in my own learning as a student and aspiring teacher. Her willingness to engage in and learn from the partnership made me feel like a necessary and active participant in the development of the course.

When asked about the benefits of having a consultant, my partner described the value of consistent support, encouragement, and pedagogical exploration:

Some teaching practices take repeated practice to improve, for example, clarity of presentation, time management, and having an observer regularly allows me to keep working on those aspects-having a partner throughout the semester kept me on top of things. Without a student partner, I find it easy to get fatigued in the middle of the semester and to be satisfied with just covering the material without designing the most pedagogically beneficial lesson. Weekly meetings with my student partner kept my spirit up about designing the best lesson plans I could.

As a consultant, I had the opportunity to see how our ideas played out in real time, and we tried to encourage consistent student feedback. This partnership increased my capacity as an advisor, sharpened my ability to prioritize changes in the classroom, and affirmed the value of my perspective as a non-STEM student. By exploring a range of pedagogical challenges and solutions, this partnership expanded my comfort and confidence with an array of consulting responsibilities. This opportunity for growth gave me valuable experience, increased adaptability, and a further developed skill set as I moved toward my final partnership with the SaLT Program.

\section{DRAWING ON EXPERIENCE AND DEVELOPING A HIGHLY FOCUSED PARTNERSHIP}

My third partnership was more focused than those before it. My faculty partner had previous experience with the SaLT Program, and had specifically requested the help of a student consultant. My partner was confident in his teaching, reflective about pedagogical practices, and interested in pursuing a deeper analysis of the course structure and student experience. He had clear goals for what he wanted us to accomplish from the beginning, which made my role more specific than it had been in previous partnerships. In addition to my perspective as a student, I now had the experience of a consultant. I entered my third partnership feeling capable; I trusted myself and I knew that my contribution was valued. Recognizing the productive success of my second partnership, I felt equipped to offer meaningful ideas and had confidence in my consulting voice.

My faculty partner was teaching an introductory physics lecture popular with pre-med students and those considering majoring in the department. He had structured the course 
thoughtfully and wanted to experiment with specific practices around student engagement and assessments, as well as explore why students had taken the class and what they hoped to gain from it. We devised a system for gathering consistent, pointed feedback from students in order to address course issues in real time. Our goal was to reimagine how to teach an introductory STEM class with sensitivity to students' learning needs and consideration for the type of thinking they would be asked to do in higher-level courses. We received rich, informative feedback and developed a number of innovative solutions to students' challenges.

My perspective as a non-STEM student was particularly salient in this partnership because we were actively trying to revolutionize the standard structure of introductory STEM lectures. We wanted to design a course that appealed to novices, engaged students who were there solely for credit, invited participants to think critically and develop metacognitive awareness, and provided relevant context for the content covered. As a physics novice myself, I was able to recognize effective learning aides, explanations, and activities. Some students struggled with the transition from the standard rules and operations of most math and science courses to employing more creative problem-solving, which I understood. I identified with those students who took the course for a specific requirement and wanted clear expectations and precise instruction. I had collected an archive of pedagogical techniques that had been effective in my non-STEM courses, as well as the STEM courses for which I had been a consultant. My experience allowed me to formulate pointed questions about specific aspects of the course, troubleshoot challenges, and propose creative solutions.

When asked what was most beneficial about working with a student partner outside of his discipline, my partner shared this comment:

There was a set of eyes on me and my classroom atmosphere that was not concentrating on trying to learn the material, but focusing on aspects that are separate from the material, but nevertheless crucial to a successful class. My manner of delivery, the way I address students, the wording I use to describe things; all elements that don't often receive enough attention, but could contribute immensely, or detract severely, from the quality of my presentation. Having a student partner gave me insights into teaching that are almost impossible to be gathered in any other way. A student in my discipline, or even a similar discipline, might more easily become engaged in the material, rather than remaining aloof, and able to see the classroom dynamics from a distance.

In this last partnership, I strengthened my ability to fine-tune pedagogical practices according to feedback and desired outcomes, and I developed a heightened capacity for determining what required immediate adjustment and what could be incorporated into future plans for the course. Instilled with confidence from my first two partnerships, I was free to expand my skills as an effective collaborator, analyst, and problem-solver.

\section{CONCLUSION}

An important thread that connects my three partnerships is the value of my perspective as a non-STEM student in the realm of STEM consulting. While at first I felt out of my element, I 
discovered that observing teaching techniques, understanding student reactions and needs, and offering constructive feedback did not require an understanding of the discipline. In fact, my lack of familiarity with the subjects allowed me to focus on the clarity of my partners' instructional styles and highlight disciplinary norms that may have been challenging to new students. I did not know how a chemistry lab or a physics course was typically structured, so it was safe for me to question everything. Additionally, my three faculty partners each expressed interest in moving beyond the modus operandi of hard science courses, and my experiences in differently formatted classes became valuable fodder for pedagogical suggestions.

Within each partnership, we considered the importance of critical thinking, open-ended questioning, discussion, and context for material. The professors wanted students to connect science and math to the larger world. They wanted to encourage deeper thinking and understanding, not surface-level recitation of concepts. Exploring pedagogical methods that supported this form of learning did not require me to comprehend the material; rather, I considered the type of questions being asked, how students were solving problems, and what opportunities existed for meaningful participation. Furthermore, I identified with many of the students in my placement courses, especially those who were non-STEM students themselves. I shared my interpretation of students' motivations and learning needs with my partners and helped them to establish practices that considered these factors while achieving their own goals for the class. Despite coming from a different discipline, my own student experience was highly relevant and informed much of my work with the SaLT Program. My lack of STEM expertise was no impediment to my success as a consultant, and it was often an asset.

As a consultant, leaving the comfort zone of familiar subjects supported me in transcending my own deficit assumptions about my expertise and abilities. My faculty partners appreciated the insights and creative solutions that were made possible through our collaboration as we revisited our preconceptions about STEM courses: their apparent rigidity, opacity, and stressful rigor. We strived to broaden the use of critical thinking and discussion in traditionally lecture-dominated environments. We explored different styles of questioning and assessment. We invited consistent student feedback on course adjustments and ventured to make content more relevant and accessible. Our partnerships expanded pedagogical boundaries and considered the impact on the student experience of every modification. Ultimately, my disciplinary differences with my partners made for rich, supportive, and innovative collaborations and exciting educational insights.

\section{NOTE ON CONTRIBUTOR}

Natasha Daviduke is a recent graduate of Haverford College. She was awarded the degree of Bachelor of Arts in Political Science with a minor in Education, and the distinction of magna cum laude with departmental honors. During her time at Haverford, she worked as a student consultant in a pedagogical partnership program. 